\title{
Poliomyelitis in Ancient Egypt?
}

\author{
Francesco M. Galassi ${ }^{1} \cdot$ Michael E. Habicht $^{1} \cdot$ Frank J. Rühli $^{1}$
}

Received: 16 August 2016/Accepted: 18 September 2016/Published online: 24 September 2016

(C) Springer-Verlag Italia 2016

Although asymptomatic in $95 \%$ of cases, in $1 \%$ of them poliomyelitis involves the central nervous system resulting in muscular weakness and acute flaccid paralysis. This has meant a heavy health burden for millions in the past. Global efforts combining surveillance, financial support to developing countries and immunization in the last 30 years have achieved a $99 \%$ decrease in cases of poliomyelitis. However, since no real cure exists, a lot of effort has still to be made [1].

The antiquity of the condition is accepted, and commonly even traced back to Ancient Egypt. Two lines of evidence are adduced, pictorial and paleopathological. The ca. 1500 BCE stele of a priest called Ruma with a shorter leg and helping himself with a stick (Copenhagen, Ny Carlsberg Museum ÆIN 0134) is considered to be one of the first representations of a polio victim [2]. The famous relief in Berlin (Egyptian Museum Inventory 15000) showing a late Amarna royal couple (ca. thirteenth century BCE) is also regarded to show the king as a polio victim with a shortened leg using a cane, yet it is even possible that the relief is a counterfeit or the clumsy work of a lesser artist [3].

Pharaoh Siptah's (1205-1187 BCE, Cairo, National Museum CG 61080) mummy shows a severely deformed Pes equinovarus-like left foot and a shortened left leg, a

M. E. Habicht: Co-first author.

Francesco M. Galassi

francesco.galassi@iem.uzh.ch

1 Institute of Evolutionary Medicine, University of Zurich, Winterthurerstrasse 190, 8057 Zurich, Switzerland situation also encountered with the clubfoot of KhnumuNekht (ca. 2500 BCE, Manchester Museum, Inv. No. 21471): these may be interpreted either as evidence of neuromuscular disease suggestive of poliomyelitis infection [4] or (especially Siptah) as congenital malformations [2] or mummification-produced modifications.

In conclusion, while the paucity of potential cases identified may confirm that even in the past only a small percentage of cases manifested a full clinical syndrome, pictorial evidence alone gives no definitive proof, still lacking from mummies. Until further incontestable paleopathological data are produced, the presence of poliomyelitis in Ancient Egypt should be considered speculative.

Acknowledgments The authors wish to thank the Mäxi Foundation for financial support of this research.

\section{Compliance with ethical standards}

Conflict of interest The authors declare that they have no conflict of interest.

Ethical statement This article does not contain any studies with human participants or animals performed by any of the authors.

\section{References}

1. WHO Poliomyelitis. Online at: http://www.who.int/topics/polio myelitis/en/. Accessed 11 Aug 2016

2. Leca A-P (1971) La médecine egyptienne au temps des Pharaons. Roger Dacosta, Paris

3. Krauss R (2009) Der Berliner „Spaziergang im Garten“-Antiker Murks oder moderne Fälschung? mit einem Exkurs über Heinrich Schäfers Ägyptenaufenthalt 1898-1901. Palarch's J Archaeol Egypt Egyptol 6(1):1-20

4. Mitchell JK (1900) Study of a mummy affected with anterior poliomyelitis. Trans Assoc Am Phys 15:134-136 